\title{
MUDAR A REFERÊNCIA PARA PENSAR A DIFERENÇA (estudo dos gêneros na crítica literária)
}

\author{
ANA VICENTINI
}

Se fôssemos fazer um breve histórico do desenvolvimento dos estudos sobre mulher e literatura no Brasil, o ano de 1987 mereceria, sem dúvida, uma atenção especial. Além do Grupo de Trabalho Mulher e Literatura da Associação Nacional de Pós-Graduação em Letras e Lingüística (ANPOLL), que tem nesse ano seu segundo encontro com um número expressivo de novos membros, são realizados dois seminários nacionais: a) Repensando a Diferença, organizado pelo Centro Interdisciplinar de Estudos Contemporâneos da Universidade Federal do Rio de Janeiro e (b) o I Seminário Nacional sobre a Presença da Mulher na Literatura, promovido pelo GT Mulher e Literatura da Universidade Federal da Paraíba.

A realização desses encontros e seminários nacionais já é, por si só, significativa. Porém, para melhor caracterizarmos este panorama, deve-se somar o fato de que a academia brasileira, em particular as áreas de literatura, artes e comunicações, está dando mostra de uma certa inquietude perante os estudos críticos tradicionalmente desenvolvidos em seu interior. Várias circunstâncias vêm contribuindo para a emergência desse clima de mal-estar. Dentre elas, merece ser destacada a ausência de mulheres escritoras do cânone literário. O incômodo face a essa ausência ou exclusão é grande: a maior parte dos trabalhos apresentados nos seminários acima mencionados teve como tema central de sua investigação obras de escritoras nacionais ou estrangeiras que habitualmente estão ausentes do cânone. Também merece atenção a substancial disseminação, no Brasil, da teoria - crítica literária feminista, desenvolvidas na Europa e nos Estados Unidos nas últimas décadas.

Mas, quem vem se inquietando a respeito da ausência de escritoras do cânone literário? Uma rápida passada de olhos pelos auditórios desses seminários é suficiente para responder à questão: dos estudos literários sobre a mulher têm ocupado basicamente as mulheres.

Este brevíssimo racconto traz consigo reverberações perturbadoras: de assuntos de mulher se ocupam as mulheres. Em outras palavras, será que não estamos reencenando a quase eterna tragicomédia "Isto é coisa de mulher"? Será que não estamos reafirmando a sólida tradição de nos ocuparmos dos assuntos "femininos" (e querem algo mais adequadamente feminino do que os estudos literários, sobretudo de escritoras?), enquanto nossos colegas se ocupam das obras importantes, sérias, transcendentais?

Ani Vieentini é professora na Universidade de Brasília.

" Publieado em Cadernos de Pesquisa. Fundaçăo Carlos Chagas, São Paulo. n.70. 
Essa divisão sexual da comunidade literária deve ser examinada com cuidado, devido ao fato de existirem, em sua origem, juízos valorativos a respeito do gênero. Na divisão apontada entre o mundo próprio das mulheres e o dos homens (divisão esta que não é privilégio dos estudos literários), o campo semântico empregado para exprimir o universo feminino de imediato se imbuiu de acepções negativas. "Coisa de mulher" é uma expressão que se desdobra em uma série de outros significados, tais como: coisa sem importância, bobagem, perfumaria, frivolidade e vários outros. Bem, uma outra pergunta se impõe neste ponto: que lógica lingüística ou conceitual equivale "mulher" a "sem importância" e homem à "importância"?

Entre o signo mulher, arbitrariamente construído para designar indivíduos do sexo biológico $\mathbf{X X}$, e seus correlatos pejorativos há uma lei que transcende a qualquer lei da lingüística e da sinomínia. A transformação do sexo biológico em uma outra categoria, e a colocação desta em um universo semântico pejorativo é explicada com bastante rigor e precisão pela teoria feminista, através de sua categoria central de análise - o gênero. Antes de nos concentrarmos na discussão do gênero enquanto categoria analítica, algumas considerações sobre o arcabouço teórico do qual ele emerge se fazem necessárias.

Em um ensaio intitulado "Sobre as teorias sexuais das crianças", Freud afirma que: "se pudéssemos nos despir de nossa existência corporal, e pudéssemos ver as coisas desta terra com olhos frescos, como seres puramente pensantes, de um outro planeta, por exemplo, nada nos chamaria mais a atenção do que a existência de dois sexos entre os seres humanos, os quais, embora parecidos em vários aspectos, marcam a diferença entre si através de signos externos tão óbvios". 1

Estabelecendo uma analogia com a imagem utilizada por Freud, podemos dizer que o pensamento feminista é como este ser pensante de outro planeta que observa cs sexos e suas relações sociais a partir de uma perspectiva estranha, alienada (no sentido brechtiano do termo). Seu olhar alienado nos revela não apenas as marcas incisivas da diferença entre os sexos, mas, sobretudo, a não correspondência entre o dado biológico e o "signo externo", este último denominado sucintamente de "feminino" e "masculino". Em outras palavras, este "alien" ideológico chamado feminismo não só aponta para a acirrada distinção sexual existente, como desvenda também o fundamento arbitrário, não natural, da mesma. O feminismo, enquanto modo particular de ver o mundo e os seres, soma-se ao pensamento sociológico que entende a realidade enquanto realidade construída. A partir dessa concepção, o sexo (fato biológico) não predetermina o gênero (fato construído). Masculino e feminino são identidades sociais configuradas ao longo de processos de significação.

$\mathrm{Na}$ cadeia de relaçōes sociais, a relação entre os gêneros ocupa, na visão ocidental, uma posição central. As contradições inerentes a cada gênero adquirem, na relação social, um caráter antagônico, o qual, como em toda

1FREUD, Sigmund. Sobre as teorias sexuais das crianças. Apud MICHEL, p.79, (Tradução minha). ligação desta natureza, leva à hegemonia de um membro sobre o outro. Desta forma, além de desvendar os fundamentos culturais da construção dos gêneros, o feminismo se ocupa, com igual ou maior vigor, em demolir as bases da dominação de um gênero sobre o outro.

A espinha dorsal desta relação de opressão é atribuída pelo pensamento feminista ao que chamamos de "ordem patriarcal", isto é, à ordenação simbólico-conceitual do mundo de acordo com um princípio básico: a Lei do Pai, ou, como prefere Jacques Lacan, o phallus. É evidente que em tal tipo de ordem cultural, a entrada da mulher e a construção de sua identidade dão-se de maneira não apenas distinta da do homem mas hierárquica, desigual. Dentro de uma ordem social estruturada sobre a norma masculina, fálica, a mulher deverá ocupar uma posição marginal, inferior, submissa, de modo a não pốr em cheque a validade da supremacia do princípio masculino.

Falei anteriormente que este modo de ver o mundo a que chamamos de feminismo se constitui a partir das contradições sócioculturais que informam a relação entre sexo e gênero. Com este tipo de gênese, é evidente que o feminismo não se constituirá em um modelo explicativo homogêneo e monolítico; pelo contrário, estamos à frente de um complexo de visões e práticas articuladas em torno de um ponto de vista básico: a análise e a contestação da estrutura patriarcal da nossa sociedade. Apesar deste eixo comum, o feminismo produz vários modos de ver e explicar a constituição dos gêneros e a opressão de um sobre o outro. Estas diferenças teóricas se tornam facilmente perceptíveis na forma pela qual cada uma dessas tendências compreende e analisa o gênero.

Conforme afirmado acima, a relação entre o sexo e o gênero é mediada por vários aspectos de natureza social, histórica e simbólica. E justamente na análise desta mediação, na ênfase dada a alguns aspectos em detrimento de outros e, conseqüentemente, na sua resolução política, que vão emergir as diferenças conceituais na teoria feminista. De acordo com os objetivos deste trabalho, vou abordar somente as tendências teóricas mais significativas para 0 campo literário.

Os compêndios e antologias de crítica e teoria literária feminista publicados ultimamente (Moi, 1985; Eagleton, 1986; Humm, 1986 e Weedon, 1987) identificam duas correntes teóricas bastante distintas e expressivas dentro da crítica feminista: a corrente chamada de anglo-americana e a francesa. Apesar do sério risco da simplificação didática, é importante ressaltar que tal categorização traz uma contribuição significativa à Teoria Feminista, na medida em que a sistematização deste pensamento é condição primordial para torná-lo acessível a um número maior de pessoas e, sobretudo, para constituí-lo em um corpus teórico mais sólido.

$\mathrm{O}$ receio de ser simplista ou redundante me impede de realizar uma análise mais detalhada destas duas correntes crítico-teóricas: para tanto seriam necessárias não apenas muito mais páginas, como também uma grande dose de originalidade e criatividade para trazer algo de novo além do que já fol elaborado, por exemplo, por Toril Moi, Mary Eagleton e Chris Weedon.

Com base no trabalho por elas desenvolvido, gostaria de resgatar não exatumente o que fonsado sobre o gênero por essas duas correntes críticas, mas insistir nas implicaçóes metodológicas, conceituais e políticas que

Organen 16/1989 
se evidenciam na existência da própria diferença entre os conceitos de gênero desenvolvidos por cada corrente. Dito de outra forma, o fato de existirem pelo menos dois modos teóricos de trabalhar com o gênero dentro da teoria e crítica literária feminista é indicativo da impossibilidade de lidarmos criticamente com um conceito único, fixo e positivo do gênero.

Em linhas bastante gerais, pode-se dizer que a corrente anglo-americana teoriza criticamente sobre o gênero no processo literário a partir do gênero da autora ou autor do texto ficcional. A influente crítica Elaine Showalter, por exemplo, identifica dois momentos ou, até mesmo, dois estágios na trajetória da crítica literária feminista. O primeiro deles, chamado por ela de crítica feminista ("feminist critique"), se ocupa do "estudo dos estereótipos femininos, do sexismo dos críticos e dos papéis limitados que as mulheres desempenham na história literária".2

Em contrapartida a essa orientação masculinizante, Showalter começa a demarcar o terreno para a construção da "ginecrítica" (gynocritics), ou seja, o estudo da literatura de mulheres, feito com base em modelos teóricos desenvolvidos a partir de um novo conhecimento acerca da experiência da mulher, o qual é adquirido através do estudo de suas obras. Em um estudo posterior, Showalter estabelece uma distinção entre o que ela caracteriza por obras escritas por mulheres e a "literatura de mulheres" (female iterature). Esta última se refere à "articulação... proposital e coletiva... da experiência das mulheres... guiada por seus próprios impulsos... em direção à auto-expressão autônoma".3

De imediato, o caráter utópico desta divisão pensada por Showalter impede sua utilização enquanto categoria de análise. Como podemos aceitar teoricamente uma manifestação "impulsiva", "livre", que vai desembocar na "auto-expressão autônoma"? É como se, num passe de mágica, a força da experiência das mulheres, tornada consciente e expressa, pusesse por terra todos os constritos patriarcais que interferem negativamente na criação literária feminina. Além disso, a herança empírica da crítica literária norte americana está fortemente presente aqui. Showalter vê a experiência da mulher como base para um novo conhecimento mais verdadeiro e menos alienado de nós mesmas que seria veiculado pelas próprias obras. $\mathrm{O}$ problema é que, mediando esta experiência e sua expressão literária, estão diversos fatores - desde a consciência da autora até as estruturas de composição do texto - que interagem na elaboração do material ficcional, transformando-o em uma outra "coisa", distinta da experiência de sua autora. Portanto, balizar um texto enquanto expressão de um novo conhecimento, tendo por base apenas o gênero de sua autora, é praticamente não só um sexismo às avessas, como também uma redução do próprio espectro crítico da teoria literária feminista.

A preocupação com o gênero no processo de composição da obra literária de mulheres, ou seja, com uma poética do gênero feminino, também está presente no trabalho de duas outras críticas norte-americanas que vêm exercendo uma influência significativa na crítica literária feminista: Sandra

2SHOWALTER. 1984.p.130

3SHOWALTER. 1985, p 4 .

Oranen $16 / 1989$
Gilbert e Susan Gubar. A questão central de seu pensamento pode ser sintetizada no estudo que elas desenvolvem sobre a criação literária, em particular sobre o ato da escrita enquanto uma prática eminentemente masculina. A partir daí, Gilbert e Gubar procuram identificar a posição da mulher escritora, dividida entre as imagens de "anjo" e "monstro", construídas pelo imaginário masculino. A criacão literária só será possível se estas imagens forem destruídas, se esta identidade fabricada e polarizada for desestabilizada. Porém, Gilbert e Gubar, conscientes do poder da cultura sobre as identidades e, conseqüentemente, da dificuldade em superar esta polarização, apontam para o seu inevitável desdobramento: "a mulher escritora percebe, com dor, confusão e revolta, que o que ela vê no espelho é freqüentemente uma construção masculina... uma criança radiante e totalmente artificial" 4 Entre ela e sua imagem no espelho, isto é, entre sua identidade real e sua identidade construída neste espelho masculino, instaura-se uma tensão, uma ansiedade que vai permear a literatura de mulheres, particularmente a literatura feita pelas inglesas do século XIX

Mesmo com essa pincelada nas idéias de Gilbert e Gubar desenvolvidas no quase-clássico da crítica literária feminista - The madwoman in the attic, percebe-se um problema de natureza semelhante ao apontado no pensamento de Elaine Showalter - a equivalência imediata entre a experiência pessoal da escritora e sua expressão literária. Para elas, o conflito de identidades vivenciado pela mulher escritora terá seu correlato na construção de personagens femininas loucas, que se constituirão na expressão esquizofrênica entre o eu real da autora e seu eu masculinamente espelhado.

A análise de Gilbert e Gubar sobre o problema de gênero na literatura de mulheres nos coloca uma questão fundamental: se admitirmos que a existência do eu dividido, do conflito entre a realidade ontológica de mulher e seu espelhamento patriarcal for um conflito consciente em todas as escritoras, teremos, então, que toda a literatura feita por mulheres é uma literatura feminista; que não existem escritoras que tenham produzido ou que ainda produzem textos em que esta consciência crítica absolutamente não está presente. Dito de outra forma, a experiência da escritora enquanto mulher não avaliza a existência de um texto literário crítico sobre a questão dos gêneros. Mesmo quando esta experiência se transforma em consciência crítica, esta tão pouco pode ser tomada como garantia de um texto literário feminista, isto é, de um texto literário que analise e desconstrua as noções patriarcais de gênero.

O eixo metodológico que permite a aproximaç̃o entre o pensamento de Elaine Showalter e o de Sandra Gilbert e Susan Gubar pode ser encontrado de maneira explícita nos títulos de um de seus respectivos trabalhos. Em ambos os casos, encabeçando um trabalho crítico-teórico da maior relevância, tem-se o seguinte título: "Por uma poética feminista".5

Um resgäte da etimologia pode ser-nos iluminador: poética vem do grogo poiesis e equivale ao corpo de leis e aspectos de composição da obra

AGILBERT E GUBAR, p. $17-8$.
SEHOWALTER, 1985. GILBERT \& GUBAR, 1984.

Orgenen 16/1989 
de arte. ${ }^{6}$ Nesse sentido, o trabalho das críticas norte-americanas deve inspirar uma reflexão maior por parte da teoria literária feminista. Os problemas metodológicos e conceituais assinalados em relação ao pensamento de Showalter e de Gilbert e Gubar sugerem-nos que a análise do gênero da instância geradora deste texto pode não ser a via mais frutífera para a construção de um novo modelo teórico. Em outras palavras, gostaria de argumentar que a construção de uma poética feminista talvez não seja, no momento o caminho crítico mais adequado para ser trilhado. Antes de sugerir algumas alternativas, gostaria de examinar sucintamente uma outra proposta de análise crítica dos gêneros na literatura: a corrente francesa.

Fortemente influenciada pela teoria psicanalítica, a vertente francesa da Teoria Feminista traz uma contribuição mais radical do que sua correlata anglo-americana, tanto em termos políticos quanto teóricos (Marks e de Courtivron, 1980). De maneira igualmente distinta das anglo-americanas, as teóricas feministas francesas se concentram nos campos da lingüística, da semiótica e da psicanálise e não se detêm explicitamente sobre o campo literário (Moi, 1985). Assim sendo, vou abordar aqui somente um conceito desenvolvido pela teoria feminista que remete diretamente ao terreno literário e que tem por objetivo analisar e explicitar a noção de gênero - o concei to de escritura feminina (écriture féminine).

Apesar de explicitamente advogar a não-correspondência entre sexo e gênero, as teóricas da écriture feminine, e em particular Hélène Cixous, elaboraram o conceito a partir da libido feminina, isto é, a partir de uma base psíquica, simbólica, mas que não se desprende inteiramente da base biológica. Nesse sentido, Cixous afirma que "a escrita tem sido regida por uma economia libidinal, cultural e, portanto, política, tipicamente masculina", 7 onde o masculino é entendido como uma decorrência biológica. E é nessa economia onde a mulher é silenciada, oprimida. Daí decorre que, para Cixous, a possibilidade de mudança reside não exatamente na fala da mulher, visto que esta é sempre silenciada, mas na sua escrita, a qual deve servir como "trampolim para o pensamento subversivo, o movimento precursor de uma transformação das estruturas sociais e culturais". 8 Esta escrita encontra sua força transformadora no próprio corpo da mulher, visto por Cixous como múltiplo em funções, "erotogêneo", isto é, com possibilidades várias de rotização e prazer. Temos aí a clara associação da escrita feminina com a libido feminina, e a base desta localizada no corpo da mulher, especialmente nos seus órgãos sexuais. Assim sendo, a escrita "se torna uma forma de dar voz à sexualidade feminina reprimida e à libido que a sustém", 9 conforme sintetiza Chris Weedon.

Contudo, Cixous nos alerta para os perigos e simplificações de uma definição de ecriture féminine: "é impossível definir uma prática feminina de escrita, e esta é uma impossibilidade que permanecerá, uma vez que esta

6PAVIS, Patrice. DiDiccionärio de teatro: dramaturgia estética, semilogia.ia. Barcelona,

Paidos, 1984.
7MARKS \& COURTIVRON de p. 249.

8 CIXOUS. p. 249.

9WEEDON. p. 168 prática nunca poderá ser teorizada, encerrada, codificada - o que não equivale a dizer que ela não exista". 10

Sem dúvida, a noção de Cixous de escrita feminina representa uma elaboração da visão das críticas norte-americanas abordadas anteriormente, na medida em que, além da experiência da mulher, tão presente na vertente norte-americana, além deste "corpo empírico", uma dimensão importante é aqui articulada: a dimensão simbólica da sexualidade e do desejo, imprescindivel para qualquer tentativa de compreensão dos gêneros, especialmente a um nível simbólico tão sofisticado como o literário. E é exatamente esta característica psíquica, simbólica, da escrita feminina que permite a Hélène Cixous apontar seus mais significativos realizadores sem a obrigatória correspondência entre sexo e gênero. Em uma nota de pé de página do ensaio "The laugh of the medusa" ("O riso da medusa"), Cixous afirma que "as únicas inscrições de feminilidade" na literatura francesa do século XX são Colette, Marguerite Duras e Jean Genet. 11

Apesar desta definição, o trabalho de Cixous, incorre, não em uma redução biológica do gênero feminino, mas em uma elaboração mítica da sexualidade feminina, aceitável dentro de uma proposta utópica de transformação, mas pouco adequada para um modelo crítico e teórico, ainda que também comprometido com um processo de mudanças.

Os dois modos de compreender o gênero expostos sucintamente acima demonstram claramente que estamos diante de um conceito que não é único, fixo. Além disso, estas diferenças de concepção implicam em procedimento analíticos distintos que levam a interpretações diversas. Mas, sobretudo, a partir dessa diferença de compreensão dos gêneros podemos inferir alguns pontos importantes para a nossa reflexão.

O primeiro deles diz respeito aos procedimentos teóricos que norteiam nossa prática crítica. Ao invés de procurarmos definir o gênero de maneira positiva, parece-me mais frutífero empreendermos análises críticas sobre seu processo de construção. Ou seja, trabalhar com um conceito de gênero definido aprioristicamente como o fazem Showalter, Gilbert, Gubar e Cixous, ainda que sob uma perspectiva inovadora, pode levar-nos a adotar estratégias de interpretação que resultarão na afirmação de uma essência fixa e imutável do gênero, distanciando-nos, assim, de uma análise crítica mais transformadora. Para tanto, a via mais adequada me parece ser a da constituição de estratégias de leitura que permitam desvendar as roupagens patriarcais de caracterização dos gêneros. Conforme aponta Michèle Barret, "ainda estamos à espera de uma avaliação substancial sobre o consumo e recepção de textos do ponto de vista da ideologia patriarcal". 12

Assim, mais do que a delimitação de leis e aspectos de composição de um texto literário feminino transformador, isto é, de uma poiesis feminista, necessitamos urgentemente pensar em mecanismos realmente-transformadores

10MARKS \& COURTIVRON de. p. 253.

CIXOUS, Hélene. The laugh of the Medusa. Apud MARKS \& COURTIVRON de. P. 249

PNEWTON \& ROSENEELT, p.78. 
de leitura e interpretação desses textos; necessitamos, em outras palavras, de uma aisthesis feminista. Esta idéia encontra suporte na noção de texto enquanto processo de interpretação. Sob este ponto de vista, um texto literário não se distingue em termos absolutos de um texto crítico - ambos são formas de interpretar algo. O primeiro interpreta o mundo, recriando-o de acordo com sua visão; o segundo interpreta o mundo ficcional, produzindo também uma visão de mundo. Nesse sentido, então, investigarmos o gênero que produz o primeiro texto, em detrimento da visão de quem investiga o gênero deste produtor, é loutorgarmos uma autoridade a essa primeira voz que nos remete às práticas mais tradicionais da crítica literária. Mais necessário do que isso é desenvolvermos estratégias de leitura que analisem essas interpretações de mundo, de que forma elas constroem ou desconstroem os gêneros. Para tanto, é essencial uma visão crítica do gênero não apenas de quem gerou o primeiro texto desta cadeia de significação, mas, sobretudo, de quem está exercendo a atividade interpretativa, quais métodos são empregados e que visão de mundo é articulada.

No caso dos estudos críticos sobre mulher e literatura, essa visão crítica da noção de gênero se faz mais necessária do que nunca. Devemos procurar fortalecer essa vertente crítica não através da semelhança biológica, mas fundamentalmente através do aprofundamento deste modo crítico de ler o mundo. E, como nos lembra Chris Weedon, "...para ler criticamente, em qualquer contexto, necessitamos de uma referência. Isto é tão necessário quanto inescapável". 13 A referência que se mostra mais rica e transformadora para nós, estudiosas (ou estudiosos) da literatura de mulheres, é, sem dúvida, a teoria feminista.

Com base no que disse anteriormente, posso concluir que somente através desta referência teórica conseguiremos realmente empreender uma análise crítica do gênero, porém não uma análise monolítica, mas poliforme e até contraditória, como se depreende das correntes críticas apresentadas acima. Somente dentro de um referencial teórico feminista conseguiremos marcar esse espaço como um locus de pesquisa de ponta dentro da produção acadêmica nacional. Fora dele, receio que estaremos melancolicamente remontando a peça "Isto é coisa de mulher", usando os velhos componentes patriarcais.

Gostaria de encerrar com uma recomendação de Simone de Beauvoir: devemos "pensar a mulher no mundo, e não o mundo da mulher".

\section{REFERÊNCIAS BIBLIOGRÁFICAS}

BEAUVOIR, Simone de. O segundo sexo. Rio de Janeiro, Nova Fronteira, 1980. EAGLETON, Mary. Feminist literary theory: a reader. Oxford, Basil Blackwell, 1986. Gilbert, Sandra \& Gubar, Susan/The madwoman in the attick: the woman writer and the nineteenth-century literary imagination. New Haven, Yale University Press, 1984.

13WEEDON. p.174.
HUMM, Maggie. FFeminist criticism: women as contemporary critics. s. Brighton, The Harvester Press, 1980.

MITCHELL, Jaliet. Women: the longest revolution. London, Virago, 1984

MOI, Toril. Sexual textual politics: feminist literary theory. London, Methuen, 1985.

NEWTON, Judith \& ROSENFELT, Deborah (ed.) Feminist criticism and social change: sex, class and race in literature and culture. London, Methuen, 1985.

PAVIS, Patrice. IDiccionario de teatro: dramaturgia, estética, semiologia ia. Barcelona, Paidos, 1984.

SHOWAITER, Elaine $A$ literature

lessing. London, Virago, 1984.

WALTER, Elaine (ed.) 'The new feminist criticism. New York, Pantheon Books,

WEEDON, Chris. Feminist practice and pos-structuralist theory. Oxford, Basil Blackwell, 1987. 